\title{
Understanding and designing sociotechnical scenarios: a multi-theoretical approach
}

\author{
Alysson Bolognesi Prado \\ Institute of Computing \\ State University of Campinas - Unicamp \\ Campinas, São Paulo, Brasil. \\ alysson@unicamp.br
}

\author{
Maria Cecilia Calani Baranauskas \\ Institute of Computing \\ State University of Campinas - Unicamp \\ Campinas, São Paulo, Brasil. \\ cecilia@ic.unicamp.br
}

\begin{abstract}
Technology evolution is pushing the limits of our comprehension of the world and of ourselves, blurring the boundaries between people and objects. To understand this interweaving of ubiquitous computer systems and their dynamic social relations different theoretical sources are necessary. Socially Aware Computing provides a deep understanding on how information systems emerge from and interact with the social context, whereas Actor-Network Theory represents a promising referential to explain how people and artifacts mutually actuate to render social structures. In this paper, we assess the paradigmatic compatibility of these two theories, proposing a blend that provides a single basis to enrich the understanding of complex scenarios for designers of sociallyaware technology. In the sequence, we present an application of such proposal in a real-world problem. Finally, we discuss how this approach can be further extended to model nondeterministic interactions involving people and devices in social situations.
\end{abstract}

Keywords- Actor-Network Theory; Socially Aware Computing; sociotechnical networks; social software design.

\section{INTRODUCTION}

When computers began to be used in business, they were data-processing machines enclosed in datacenters, under the supervision of technicians and operators. However, they soon became a working tool on office desks, supporting individual or collaborative tasks, and providing information for decisionmaking directly to their users. Nowadays, computers can be found in the houses, cars, and even pockets of people around the world, fulfilling the role of a medium of expression of interests and intentions [26] in contexts where goals and constraints may be not clear or well defined. Nevertheless, much of software development is still carried out with focus on technical aspects, with little attention to the formal and informal social aspects of the organizations and society in which they exist. Consequently, the impact of the introduction of computer systems has unexpected consequences on the social groups involved, either positive or negatively.

We understand a sociotechnical scenario as a situation in which not only the human-technology interaction is relevant for designers, but also the human-human and technologytechnology interplay requires the same degree of attention. Since each of these relationships are addressed by different

This work is partially supported by São Paulo Research Foundation (FAPESP) grants \#2015/16528-0 and \#2015/24300-9, and CNPq grant \#306272/2017-2. scientific areas, such as Human-Computer Interaction, Sociology, and Computer Engineering respectively, a holistic approach demands a coordination of some independent theoretical sources.

Socially Aware Computing - SAC - is a design model proposed by Baranauskas [5] to support the design of interactive systems, articulating ideas from Organizational Semiotics [39, 40], Participatory Design [52] and Universal Design [41] to create a socially responsible vision of the design of computer systems. In this model, design is a social process with focus on both characterization of the design situation and proposition of solutions.

The Actor-Network Theory (ANT) [34] is a theoretical and methodological set of Sociology, which arose in Social Studies of Science and Technology to understand the relationships between scientists, and was expanded to social phenomena in general. This theory aims to offer an alternative approach to the study of social phenomena, providing the interested observer with a "sensitivity" to capture how these phenomena work. It states that the only forces responsible for sustaining social aggregations come from their participants, and acknowledge the participation of both human and non-human entities. This feature has been attracting a growing interest in Computer Science research communities, as a simple query on ACM Digital Library suggests (Fig. 1).

In this paper, we extend the theoretical framework of SAC, articulating it to the theoretical reference of ANT, to complement and refine the characterization of the social context in which a digital artifact participates. Since they are

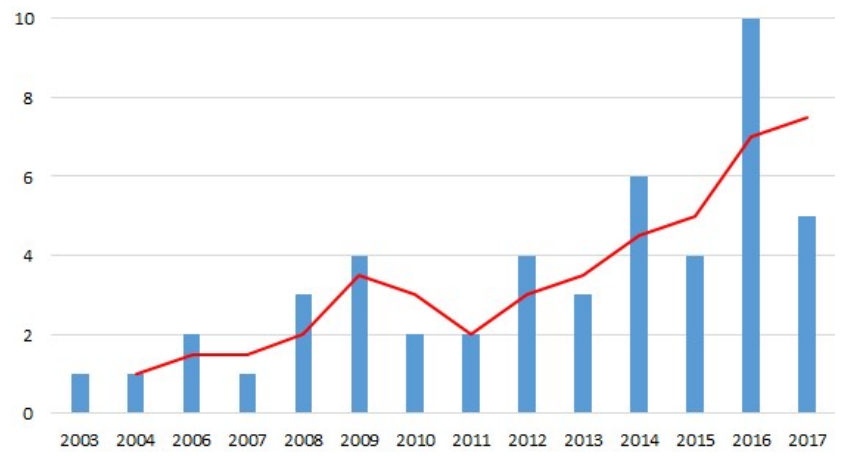

Fig. 1. Number of papers per year, found in the ACM Digital Library when searching for "Actor-Network Theory". Red line is the moving average with period 2. Data retrieved in January 11, 2018. 
theoretical and methodological sets arising from independent scientific paradigms, it is important that any effort towards their merge should not be an ad hoc process, but instead, should be driven by their stances regarding concepts of the philosophy of scientific knowledge [47]:

- Ontology: definition of what is accepted as existing beings;

- Axiology: clarification on the purpose and values of the producer of knowledge;

- Epistemology: relationship between subject and object of research;

- Methodology: establishes valid conducts and procedures for obtaining knowledge.

In the following sessions, we provide a summary of the theoretical framework of ANT, illustrating its main concepts with examples from other works, which applied this theory in the description of sociotechnical systems. Next, we present main concepts of SAC and discuss the philosophical stances of both underlying scientific paradigms. Finally, we present and discuss a proposal to merge these two theories and the implications for the design of computer systems, aiming at the understanding of social participation of information systems, followed by an illustrative case study.

\section{ANT: MAIN CONCEPTS IN SOCIOTECHNICAL SCENARIOS}

In order to understand the origin and nature of social phenomena, some branches of sociology propose the general concept of agency, according to which the ability of individuals to act independently and make their own decisions by means of free will is the source of social phenomena. Then, social structures would be a consequence of the usage of cognitive and physical abilities of individuals, driven by their interests and intentions. In this context, ANT relies on its own interpretation of agency, proposing to understand social groups as chains of associations distributed in time and space. These groups depend on the continued actuation of their participants onto each other, producing a dynamic structure. An actor, therefore, is defined as any entity that acts on another, or that puts some other to act, changing a certain state of affairs.

Unlike many sociological theories, which consider society composed, produced and maintained only by people, ANT introduces the need to look also at the material reality of objects and artifacts. The social activities of these participants create associations among them, aiming to get support, to propagate forces, to forward interests, and to mobilize other partners to achieve mutual goals and benefits. These allies can be found among humans, among non-humans, but in most cases, the set of partners is heterogeneous. ANT is theoretically grounded on the principle that the basic social skills of humans are able to generate only weak ties with short range and duration $[34$, p. 65]. For the associations to become long lasting, they require non-human actors to take part on it, ensuring stability and action at distance, either by semiotic or material modes [36].
Traditionally, groups of people who interact with each other are of interest of Sociology, while groups of objects that are assembled in an orderly fashion - i.e., machines - belong to the domain of the Technology. The point of contact between people and technical devices gets attention, from one side, from the various disciplines of "human factors" and, on the other, from the social studies of science and technology [15]. ANT proposes that these phenomena should be handled together. The understanding of social reality requires that boundaries between these areas be overcome, giving more attention to the sequence of interactions rather than the nature of its participants. Fig. 2, adapted from Akrich and Latour [1], exemplifies these heterogeneous chains, showing the loci for different partial attention.

In the real world, these relationships are not always in a single row, neither the boundaries are so well defined. For example, applying ANT to understand the evolution of personal digital assistants - PDAs - in the 1990s, Allen [2] reports that when Palm Pilot was released, its target audience was chosen to be busy executives who needed access to simple applications for management of personal information. On the one hand, the battery would have to be small, requiring a CPU with limited processing capacity. It was also chosen a penbased input mechanism (stylus), thereby eliminating the need of a keyboard. In other words, human actors shaped in many ways the new object under creation. On the other hand, given the CPU limitations and poor algorithms for handwriting recognition available at the time, data entry algorithm did not recognize normal handwriting, only a simplified alphabet called Graffiti, compelling the user to learn to write in a new way. This is an example, schematically represented in Fig. 3, of a set of non-humans forcing a change of behavior on human actors.

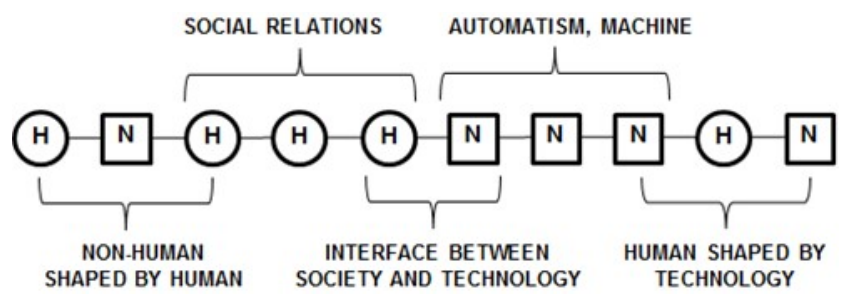

Fig. 2. Chains of associations in a heterogeneous social phenomenon. Rounded figures denote human actors, while squares represent the nonhumans.

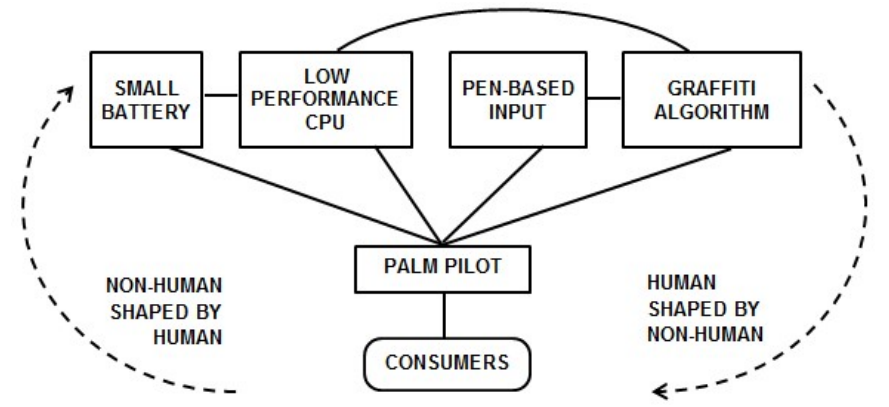

Fig. 3. Simplified chains of associations established during the development of Palm Pilot, to illustrate the spread of influences between humans and non-humans. 
The process of building associations between actors is named translation. It happens when an actor, wishing to change certain state of affairs, find other actors whose actions and skills can be beneficial, encourage their interest in associate with one another, and control their behavior so that their actions have some predictability over time. This effort creates order, in the form of devices, institutions and communities.

Akrich and Latour [1] suggest that these interference and negotiations occur not only between each pair of actors, but also in longer chains of associations including several participants. Interests and intentions are forwarded through existing associations until reaching the actor who others wish to influence. When actors keep connected, forming a network, the consequences of success or failure spread through the associations; so, there are mutual interests in the success of their partners. Callon [12] states that a successful translation is carried out in four moments: problematization, interessement, enrolment and mobilization of allies.

There are several strategies on the problematization for starting to assemble a network, for instance, following existing chains of associations in search of new allies. Spiess [54] used ANT to analyze the emergence of LibreOffice suite. He describes the effort of two Brazilian programmers to translate a code, which previously belonged to StarOffice and then to Sun Microsystems. At first, these Brazilian developers tried to contact another free software evangelist, who had previously volunteered himself for the translation to Portuguese, but they had no success. They then established contact with members of the OpenOffice.org project, hosted by Sun Microsystems, who assigned them officially the translation task. Next, they summoned up more volunteers using e-mail forums. The whole sequence of associations is depicted in Fig. 4.

In the interessement phase, Latour [32] categorized some general strategies (Fig. 5) that an actor can use, applying different persuasion forces on the others, to change their "regular behavior" towards a desired one:

1. An actor gives up part of their interests in order to align with stronger actors;

2. An actor can convince a stronger one to change their goals;

3. The weaker actor must convince the stronger one that there is an obstacle in their plans, and suggest an alternative route beneficial to both;

4. It may consist in inventing new groups and objectives, making successive unnoticeable deviations from the original path, or successive approximations towards a target, occurring commonly in a scenario with several participants;

5. An actor becomes essential. In this case, no negotiation is required.

The work of Faraj et al. [19], which analyses the evolution of web browsers from the perspective of ANT, brings several examples of translations. In 1993, one of the first versions of Mosaic web browser tried to encompass other protocols, such as Gopher and FTP, in addition to its primary functionality of

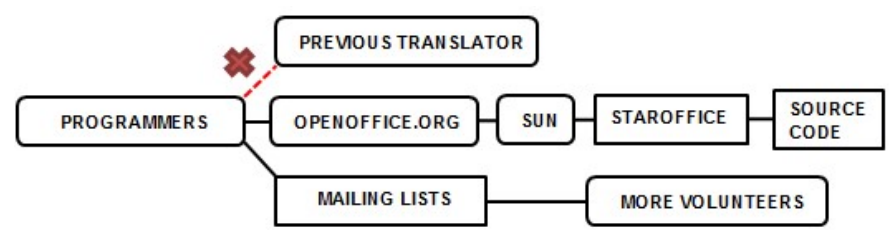

Fig. 4. Example of the rise of LibreOffice software.

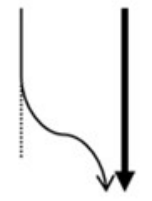

Mode 1

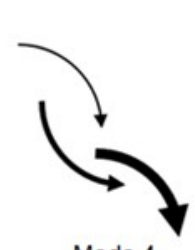

Mode 4

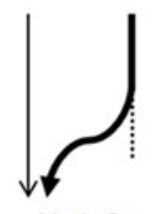

Mode 2

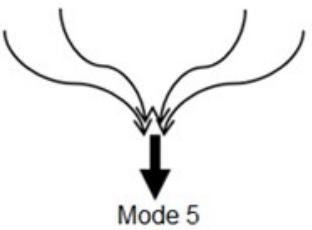

Fig. 5. Modes of translation. Adapted from [34].

rendering html pages retrieved via http, intending to attract more users. That is, a weaker and less known actor changed its properties in order to benefit from stronger players translation mode 1. In 1995, Netscape Corporation decided to improve their browser adding interactivity and dynamism. Plugins for Java applets and PDF viewers were incorporated within the browser, requiring a change of route both by Netscape, who had to create APIs to support plug-ins, and the application providers, who had to adapt their codes to run within a browser - mode 3. In parallel, Microsoft tried to promote its Internet Explorer relying on a strong integration with its well-established Windows operating system. Therefore, Windows had to be modified, for example, to match the idea that the browser would become the standard user interface to access local files. A stronger actor was diverted from its original path to strengthen the weaker - mode 2. In 1996, Lawson Software Company became the first one to use a web browser as a user interface for their ERP application. Immediately, other vendors such as SAP, Baan and PeopleSoft rushed to provide the same type of web interface. The browser had become an actor able to attract by itself the interest of others, which in turn changed their ways in order to benefit from an existing actor - mode 5 .

In cases where the interessement is successful, translation reaches the enrollment phase, in which actors may accept their new roles, outlining responsibilities. At this stage, Callon [12] states that strategies range from the consent without discussion to the imposition by physical force. Returning to the example of Faraj et al. [19], the effective enrollment of various actors led to the definition of what currently is understood as a web browser: a piece of software capable of supporting various protocols and software plug-ins, and not only able to provide static content, but also to serve as an interface for dynamic systems and diverse types of media. Browsers' role and behavior are well defined for the other participants: developers, 
companies, content providers and users share a general concept of what it is.

Any achieved social structure is temporary and unstable. Actors' arrangements are subject to decay, due to internal changes of interests, unexpected behavior, or external influence of new participants. At this step, known as mobilization of allies, Latour [32] points out two major concerns: to find the weakest link in the chain of associations; and to seek for more allies to shield the weakness and help to maintain the network cohesive. It requires assessing whether the actions undertaken by the actors already enrolled are being propagated, and if necessary, promoting new translations to bring more participants to the network, creating alternative paths to ensure the effectiveness and durability of associations.

For example, Lee and Oh [37] used ANT to describe the competition between the wireless network security standard called WEP, used by the Wi-Fi Alliance Consortium, and a competitor protocol supported by the Chinese government, called WAPI. WEP had known security flaws, which featured as a weak element in the chain of associations Wi-Fi Consortium used to reach its customers. Wi-Fi Consortium had to develop the WPA standard, compatible with most of the existing hardware requiring only a firmware upgrade, and at the same time having forward compatibility with the IEEE 802.11i standard under construction. These new actors made possible to keep the other allies under control. In Fig. 6, the weak path is represented in red, the external influence in dashed lines, and the alternate paths in thin solid lines.

When translation is effective and the various actors are led to act synergistically, with support of mechanisms for mutual control, the complexity of the network can be encapsulated - or punctualised [36] - in a black-box, which can be seen as a single actor. Recovering the example of the Palm Pilot, while its developers see a complex web of interrelationships, where several components have well defined roles, users interact with the device as a black box, a single actor. This example illustrates another important concept proposed by ANT: the ontological planarity. Local and global, part and whole, are not hierarchically separated or embedded one inside the other, differing only by their connections. "The more attachments [an actor] has, the more it exists" [34, p. 217]. As represented in Fig. 7, hardware and software components are not "inside" the actor representing the device, but instead, its parts link to the whole, and distinct paths of interaction for users and developers provide distinct views.

When accidents or unexpected behaviors occur, the network that constitutes the actor is exposed, often showing heterogeneous chains. For example, companies are an aggregate of people, machines, and documents; they make decisions, have market strategies, and so on, behaving like a single actor for the society outside. For all practical purposes, the responsible for a specific behavior is not highlighted until it becomes necessary, for example, in case of liability for damage to third parties, determining if it was a human error or technical failure. When inventors, designers, and engineers create novelties, they have representations of the target users and uses for the products they develop. This intended behavior model is incorporated into the device being produced, in a process



Fig. 6. Wi-Fi Alliance mobilizing new allies, WPA and 802.11i, as a way to strengthen the network weakened by WEP, counter-attacking the threat posed by WAPI.

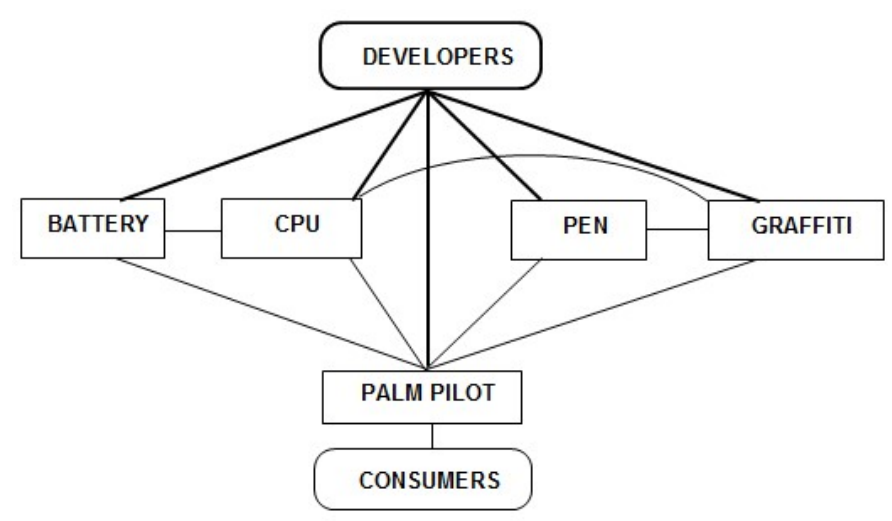

Fig. 7. Network of actors for the Palm Pilot, from the point of view of the developers and consumers.

Akrich and Latour, [1] name inscription, assigning sequences of actions or influences that its creator hopes that takes place in specific contexts.

Technological artifacts have the ability to modify the way people think and act, and can be used in a different fashion than they were originally designed for, sometimes in unexpected ways, having thus some level of independent action, what can be regarded as a kind of agency [30]. It does not mean, however, to attribute intentionality to non-human actors, but instead, we should not overlook their potential for interaction and mediation of other relationships. Humans should be treated as such, recognizing their rights, obligations and responsibilities [36]. It is clear, however, that a priori separation between humans and non-human is not essential to the understanding of a social phenomenon, because both are important to the network and no place in particular is reserved for any of the kinds.

Instead of categorizing actors according to their nature, human or non-human, ANT claims it is more important to identify the role they fulfill in the associations chains when transporting forces and influences as intermediaries or as mediators. An actor is considered an intermediary in a chain of associations when it transmits the actions received without changing them. The behavior of an intermediary is predictable and the inputs determine the outputs. A network composed only by intermediates can be easily encapsulated into a black box, regardless of how complex and intricate their relationships are. When analyzing a network, intermediary actors often stay unnoticed. On the other hand, a mediator contributes with new 
behavior for the system. Mediators modify, distort, amplify or translate incoming stimuli. They are creative and show variability and unpredictability to act on the others, resolving asymmetries and conflicts between actors. This classification is circumstantial: the same actor can act both as mediator and as intermediary under different stimuli and contexts [3].

For example, Gonçalves et al. [22] studied how online tools for collaborative work and discussion could be used for academic deliberation support. They analyzed software such as Trello and ConsiderIt. Trello allows users to create cards containing information and comments. According to users' permissions, these cards can be graphically organized in lanes and receive color codes. Location, appearance and content of each card - and of the whole board as well - are the result of the actions of all users; every card reflects the buildup of every previous action of users. However, once a card is changed, the results of last user's actions are respected by the system, being presented as is for all users. In this context, Trello is acting as an intermediary, as it forwards faithfully user's interests in change some of the board content - at least until it receives more actions. On the other hand, ConsiderIt is provided with a balancing algorithm [29], which avoids the prevalence of a single point of view, encouraging people to reflect upon and emit opinion about an issue of interest. Individual user entries are rearranged on screen by this algorithm, pondering all contributions and highlighting interesting point in both sides of argument. In this regard, as no user can force their intentions and preferences about how arguments must appear, ConsiderIt acts as a mediator, adding something of itself to the set of actions received from users and providing, from the point of view of a single user, a non-deterministic outcome.

\section{SAC AND THE DESIGN PROCESS: A BRIEF PRESENTAtion}

The Socially Aware Computing is an approach to the analysis, design and evaluation of digital artifacts with focus on their influences and consequences for the society. The usage of $\mathrm{SAC}$ in software design is extensively documented in literature; the work of Santos et al. [51] provides several examples. In the SAC design model, building a digital artifact is a social process focusing on both gathering requirements and proposing solutions [44]. The design model is both interactive and iterative, involving stakeholders to provide their distinctive viewpoints and progressively build knowledge and a common sense about the expected solution. To deal with the diversity of participants, bringing them together towards a single solution instead of segregating them, a background on Universal Design [41] is employed. Moreover, theories and techniques from Participatory Design [52] help to promote their direct involvement in the design process.

Organizational Semiotics is another theoretical root for SAC. It conceives an organization as a group of people who act together towards a purpose, and their action is coordinated by an information system composed by signs and patterns of behavior. In this information system, three layers can be found, regarding the degree of formalization and objectivity: the external informal layer contains beliefs, negotiations and uncertainties; the formal layer reflects the bureaucracy; and the technical layer is where technology and technical procedures are studied. According to SAC, the design process of a piece of

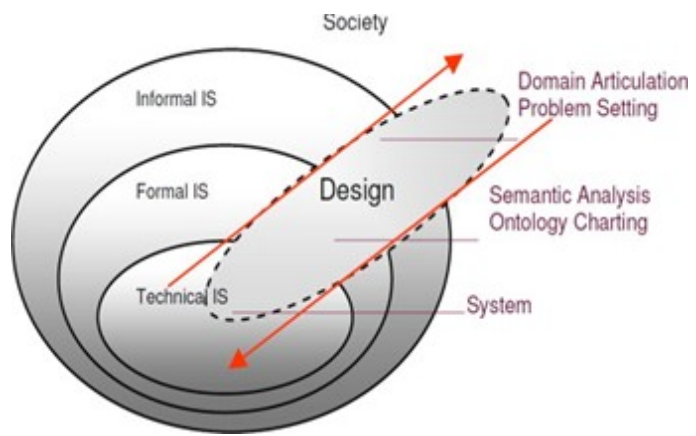

Fig. 8. SAC perspective about the design process in a social context. Extracted from [44].

software is a movement (Fig. 8) starting on the external layers and progressively reaching the inner ones; once the wishes, needs and expectations from the external layers are materialized into the technical layer, the presence and use of a new artifact propagates consequences towards outside.

In participatory activities promoted by SAC during the design process - named semioparticipatory workshops several representatives of persons potentially interested or affected by the planned new device or software are reunited and encouraged to interact among themselves and with specific artifacts. For instance, the Evaluation Frame (Fig. 9) can be printed on a board in which participant stick "post-its" handwritten with problems and questions they are currently facing, and expose ideas and solutions they foresee to be achieved using the system being built. This is a move from the outer layers (Fig. 8) towards the inner ones.

An ontology chart [40] is an artifact designed to capture the semantic level of the domain problem. It articulates the involved concepts and definitions, finding the common meanings related to the desired solution. The basic elements of semantic analysis are: affordances, agents and ontological dependencies. Affordances are social constructions that express invariant patterns of action in a certain social context. An agent is a special type of affordance, which can be defined as something that performs responsible behavior - or, in Stamper's [55] point of view, something that will be rewarded or punished according to the outcomes of their action on the environment. An agent can be a person, an organized group of people, or a society. An ontological dependence is formed when an affordance is only possible if other affordances are available. When affordance "A" depends ontologically of affordance "B", it means that "A" exists only while "B" does [10]. These elements can be drawn in a diagram where rightmost elements are ontologically dependent from the lefthand ones. Building this diagram is a move from the informal to the formal layer.

As Organizational Semiotics affirms that observing invariant patterns of behavior only makes sense within a social group - in other words, affordances and agents emerge from a society - ontological diagrams are usually drawn beginning with "society" on its left side. Basic concepts are identified, from which more complex concepts are derived. For example, Fig. 10 shows an Ontological Chart extracted from Stamper [55]: in a given society, the concept of borrowing an item from a library relies on the idea of ownership of such item. To own, 
in its turn, is ontologically dependent of an owner (library, in the example) and an owned (item). Afterwards, this kind of chart can be used as a source of information to build a UML class diagram, as shown by Bonacin et al. [10], in a move from the formal to the technical layer.

However, going to the technical layer does not mean building the software. Brain Draw [43] is a participatory prototyping technique suggested to be used to allow the involved parties to express their expectations about how the software should look like, and converge such expectations towards a single representation, meaningful for all participants. Fig. 11 brings an example of an outcome of a Brain Draw session.

The information system can be decomposed into semiotic levels, building the so-called semiotic "ladder" (Fig. 12). The three lower levels correspond to how signs are physically supported, what encoding they use, and how they can be organized; they can be projected onto the computational structure of organizations, encompassing hardware, networks, and software. The three upper levels correspond to exclusively human attributions: in the semantic layer, data is comprehended and meaning is assigned; in the pragmatic layer, the system is used with a certain purpose; and if this purpose presupposes or implies other people participating in the system, it reaches the social level. Analyzing an information system from the point of view of each of these levels can provide a broader understanding of how it operates.

Awareness of these semiotic levels must permeate all phases of design process. For instance, Baranauskas and Carbajal [7] employed the semiotic ladder as one of the artifacts in a semioparticipatory workshop to evaluate a previously built device. A physical device intended for teaching computational thinking was presented to teachers and tried by children. Afterwards, a discussion with teachers was guided using the semiotic ladder, clarifying the project in the different abstraction levels, and capturing the impact of the proposed device on the target audience. This is an example of an outward movement on the layers of Fig. 8, from the technical to the outer society.

Other artifacts and techniques were added to the original SAC core to address social and cultural issues. Pereira and Baranauskas [44] proposed a method based on Hall's [23] Building Blocks of Culture to elicit software requirements. For each building block, listed below, Pereira et al. [46] provide examples of questions that must be asked during the analysis phase, and that must be followed by identifying values each stakeholder attributes to them:

- Interaction: what interaction possibilities will the application offer?

- Association: is the application usage individual or collective?

- Learning: is it required any prior knowledge for learning how to use the application?

- Play: what kind of emotions the application may/should evoke/avoid?



Fig. 9. Picture of an actual Evaluation Frame used in a semioparticipatory workshop. From [5].

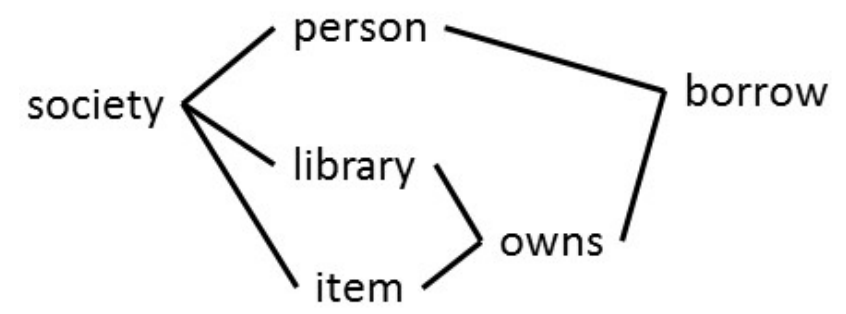

Fig. 10. Ontology chart, adapted from [55].



Fig. 11. Brain Draw example, extracted from [44]. 


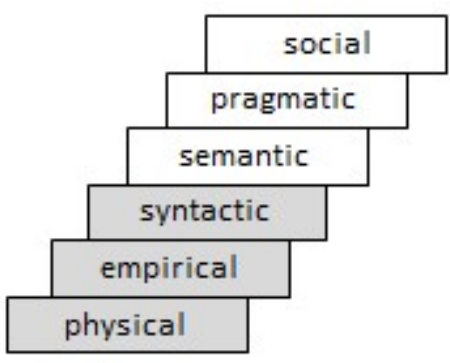

Fig. 12. Semiotic "ladder", depicting levels in which signs' presence and activity in an organization can be studied. Adapted from [39].

- Protection: can the application compromise users' safety?

- Exploitation: will the introduction of new devices generate the disposal of old ones?

- Temporality: what are the expected interaction duration and frequency?

- Territoriality: in which space the application will be used?

- Classification: are there any issues related to user's gender, age, instructional, social and economic levels?

- Subsistence: does it need a strategy for funding the application's maintenance costs?

As a result, a list of requirements related to cultural aspects and values of stakeholders can be generated, foreseeing possible impacts of these requirements on different cultural backgrounds.

\section{ANALYSING THE SCIENTIFIC PARADIGMS UNDERLYING SAC AND ANT}

From the ontological point of view, SAC is based on Organizational Semiotics, which adopts a radical subjectivism stance [39], assuming nothing exists without the presence of a knowing subject who perceives and recognizes the existence of other entities by means of actions on the environment around them. Organizational Semiotics recognizes the existence of two kinds of entities: agents and affordances. In general, agents correspond to human entities, whether individual persons or collective groups, while the affordances are patterns of behavior of these agents, being provided, allowed or imposed by non-human entities. However, under a deep analysis, this definition is sensitive to context: what differentiates an agent from an affordance is that the former should be able to act responsibly, or to him/her can be imputed responsibilities [39, p. 64]. ANT sees a social phenomenon as played exclusively by actors, and their nature - human or otherwise - is not relevant a priori. On the contrary, separating actors in different domains make it harder to explain society. The network formed by actors should not be seen as a distinct ontological level, a structure above the existence of the actors; actually, actors exist only because they are acting on each other, and the network provides this entanglement of actions.
Particularly regarding technology, the Organizational Semiotics states that, at the technical level of the semiotic "onion" (Fig. 8) which composes any organization, well defined responsibilities can be delegated to machinery - the human agent is still the holder of such responsibility. ANT agrees in this point of view [33], being equally incisive in the definition that technology is delegation. Technological arrangements are nonhuman capable of translate human interests in actual action. ANT adds that this association changes its both sides: humans are modified by changing their plans and expectations to match what the device is capable of deliver; and non-humans are "programmed" to provide the procedures delegated to them.

Axiologically, we focus the analysis on how paradigms expect the results of research to spread beyond the borders of the scientific community in which they were generated. Relationship between science, technology and society historically received many definitions and points of view. One of the most relevant is given by the so-called School of Edinburgh [9], which proposed the Strong Programme of the Sociology of Scientific Knowledge, saying that psychological and cultural conditions in which knowledge is generated are important for understanding it, and the same type of explanations must be employed for either success or failure of scientific endeavors. The name "strong programme" was given in opposition to what was named "weak programme" of the social studies of science and technology, which assumes that society biases the progress of technology away from its "natural" path, generating the common position that "human factors" are responsible for a particular scientific or technological effort not reaching its "perfect" shape.

Following the influences of Participatory Design, SAC is clearly directed towards the possibilities of promoting changes in society simultaneously to the construction of information systems [6]. ANT borrows some points of view from the Strong Programme, however criticizing and expanding its bases. Although ANT's studies suggest mutual interference between science and society, there is no clear proposal for social intervention. There are only clues of this intent, as in Latour [34, p. 259]: "it's perfectly true to say that no sociology can be happy with 'just describing' associations". Social contribution of ANT turns out to be to provide a better view of who or what are the participants of a social phenomenon, including non-human actors, to enable more effective action on society.

From the epistemic point of view, Organizational Semiotics states that "there is no knowledge without a knower" and "there is no knowing without action". The design of an information system focusses on the responsible involvement of stakeholders, instead of their accurate classification [6, p. 37]. Encouraging the participation of agents in the design process is a way to bring their knowledge to the system under development. The ontology chart [40] is employed to represent this knowledge about the existence of affordances and agents, as well as to determine ontological dependencies between them. Well-defined norm syntax is also used to represent patterns of behavior. Each new pattern is anchored to what is already known by the social group under study. 
Latour [32, pp. 88 and 89] illustrates how ANT understands the process of building scientific knowledge, providing a fictitious dialogue involving Pierre and Marie Curie, defending the discovery of a new chemical element - polonium. The dialogue goes on, the Curies providing a list of substances and actions the ore should be subjected to, in order to cast off the possibility of being an already known chemical element. In the end, no other substance behaves the same way to the list of trials:

Pierre and Marie Curie: -Here is the new substance emerging from this mixture, pitchblende, see? It makes the air become conductive. You can even measure its activity with the instrument that Pierre devised, a quartz electrometer, right here. This is how we follow our hero's fate through all his ordeals and tribulations.

Scientific Objector: This is far from new; uranium and thorium are also active.

-Yes, but when you attack the mixture with acids, you get a liquor. Then, when you treat this liquor with sulphurated hydrogen, uranium and thorium stay with the liquor, while our young hero is precipitated as a sulphuride.

- What does that prove? Lead, bismuth copper, arsenic and antimonial pass this trial as well, they too are precipitated!

-But if you try to make all of them soluble in ammonium sulphate the active, something resists ...

- Okay, I admit it is not arsenic, nor antimony, but it might be one of the well-known heroes of the past, lead, copper or bismuth.

-Impossible; dear, since lead is precipitated by sulphuric acid while the substance stays in solution; as for copper, ammoniac precipitates it.

-So what? This means that your so-called 'active substance' is simply bismuth. It adds a property to good old bismuth, that of activity. It does not define a new substance.

-It does not? Well, tell us what will make you accept that there is a substance?

-Simply show me one trial in which bismuth reacts differently from your 'hero'.

- Try heating it in a Boheme tube, under vacuum, at 7000 centigrade. And what happens? Bismuth stays in the hottest area of the tube, while a strange black soot gathers in the cooler areas. This is more active than the material with which we started. And you know what? If you do this several times, the 'something' that you confuse with bismuth ends up being four hundred times more active than uranium!

- ...

-Ah, you remain silent! We therefore believe that the substance we have extracted from pitchblende is a hitherto unknown metal. If the existence of this new metal is confirmed, we propose to name it polonium after Marie's native country.

The various substances, equipment and procedures already accepted by the scientific community are employed as intermediates, carrying actions that lead the new actor to show behavior previously unknown, until accepted as the element polonium (Fig. 13).

In another work, Latour et al. [35, p. 14] picture a hypothetical situation in which someone tries to get information about an unknown person, "C. Hervé", using his curriculum available on the web:

If for instance we look on the web for the curriculum vitae of a scholar we have never heard of before, we will stumble on a list of items that are at first vague. Let's say that we have been just told that 'Hervé C.' is now 'professor of economics at Paris School of Management'. At the start of the search, it is nothing more than a proper name. Then, we learn that he has a 'PhD from Penn University', 'has written on voting patterns among corporate stake holders', 'has demonstrated a theorem on the irrationality of aggregation', etc.

By providing such information on a website, the unknown person is able to act upon the person searching for his name, allowing her to build an "image" of who $\mathrm{s} / \mathrm{he}$ is. In both examples, ANT describes the construction of knowledge recognizing the existence of an actor who wants to know other, whether human or not, and then need to build chains of actions among them, resorting to other actors already known. As someone establishes more links and paths, they reduce the range of possibilities of what or who the unknown actor may be (Fig. 14).

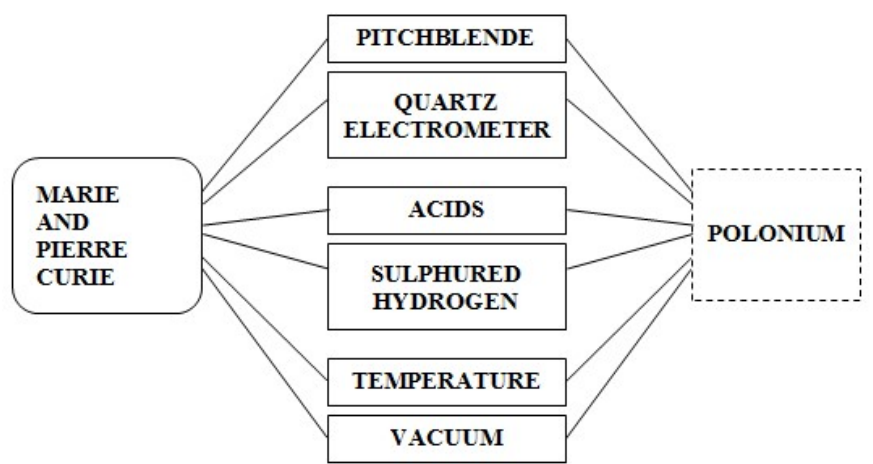

Fig. 13. Simplified graphical representation of the various actors involved in the discovery of polonium.

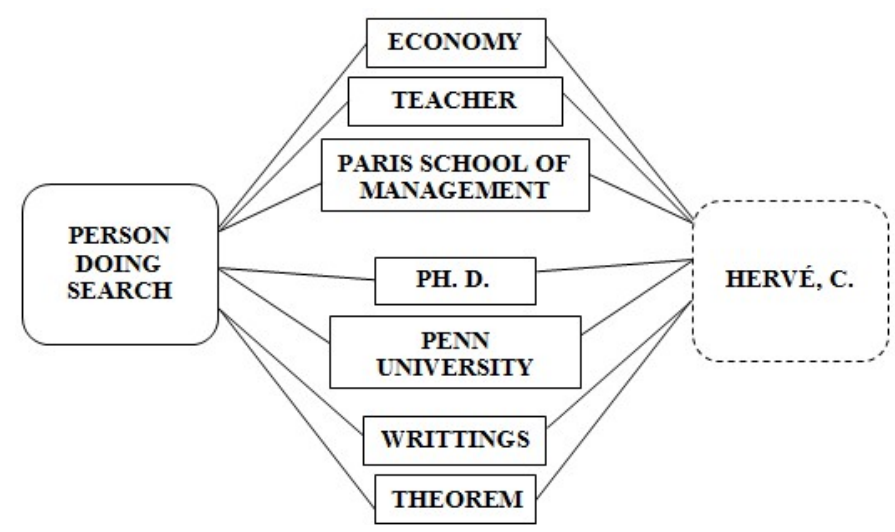

Fig. 14. simplified graphical representation of the various actors involved in the identification of a person based on the information published by him in an online curriculum. 
The methodological conduction of SAC offers a wide range of tools and methods, such as interviews, workshops and so on, including the Problem Articulation Method - PAM -, Semantic Analysis Method - SAM - and Norm Analysis Method - NAM [28]. These methods consider an organization as a group of people sharing a purpose, who need to articulate their actions to solve a problem. PAM identifies human actors - stakeholders - who can affect or be affected by the solution under scrutiny. SAM captures the ontology of the problem domain, recognizing the existence of invariant patterns of action - affordances. NAM records formally the standards of behavior and performance of the identified stakeholders, using the well-defined formula [39, 40]:

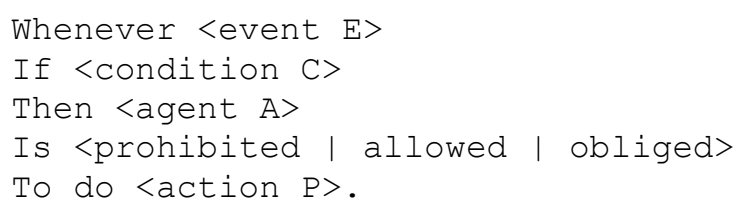

Some artifacts support these methods, for instance, the stakeholders diagram [28] (Fig. 15). The identified interested parties are arranged in "layers" that reflect the degree of impact each actor suffers or is able to offer on the system being analyzed: users and persons responsible for the operation, clients for whom the system can provide some contribution, suppliers from whom you expect some kind of input or support, and the surrounding market and community. Such artifacts are constructed collectively during semio-participatory workshops [6].

From the methodological viewpoint, ANT mostly uses face-to-face observations and detailed textual descriptions, applying ethnographic methods. It proposes to "follow the actors in their weaving through things they have added to social skills so as to render more durable the constantly shifting interactions" [34, p. 68]. Actors have their own frame of reference and the transition from one frame to another always adds some uncertainty. Human and non-human actors should be equally allowed to express themselves. ANT recommends following the actors closely, searching for entities that actually make people act, and understanding how actors recruit others to serve their purposes. When it is not possible to observe objects in situ, it is allowed to recover the history of the objects

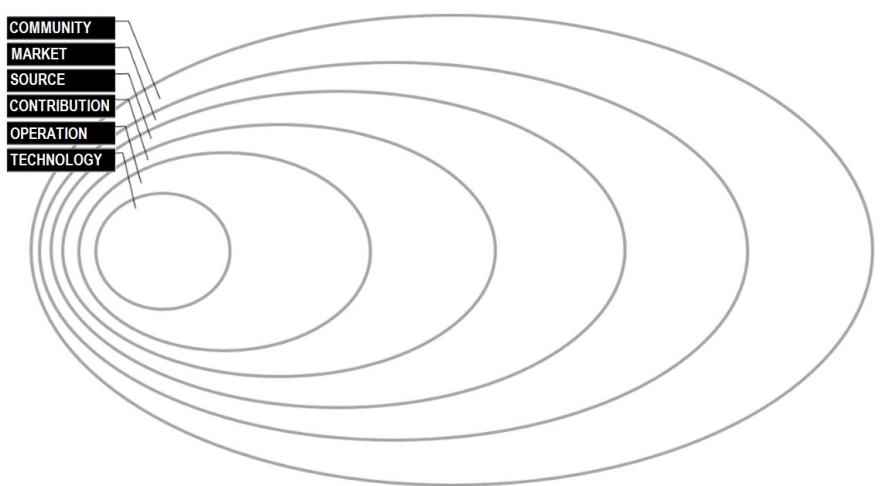

Fig. 15. The stakeholders diagram template, used by SAC to identify the multiple players involved in the development of an artifact. The layers, from the outermost to the innermost, are: community, market, source, contribution, operation and technology. and the state of uncertainty or crisis in which they were generated.

\section{ARTICULATING ANT AND SAC}

In this work, we blend ANT and SAC, keeping the theoretical core of Organizational Semiotics and resorting to interesting features of ANT. In this effort, we propose to incorporate the ontological view of ANT, making no a priori distinction between humans and non-humans, regarding both types as actors, considering only their actions and influences. Their associations into networks keep no privileged or exclusive position to one type or another. However, we chose to consider a relevant feature pointed out by Organizational Semiotics: agents are responsible entities, able to make decisions and suffer its effects and consequences. Moreover, only human actors have intentionality.

In Fig. 16, we represent graphically examples of situations in which an actor, human or non-human, are placed between two other actors forwarding an influence it receives. According



Fig. 16. Actors as intermediaries in chains of associations, transporting any given influence "A". Up: human as intermediary; Middle: non-human as intermediary; Bottom: intermediaries' social role is seldom noticed.



Fig. 17. Actors as mediators in chains of associations, changing the stimulus they receive. Up: human as mediator, translating a certain influence " $\mathrm{A}$ " into another "B"; Middle: non-human as mediator, translating a certain influence "A" into another "B"; Bottom: mediators solve conflicts and merge stimuli " $\mathrm{A}$ " and " $\mathrm{B}$ ", providing a hybrid outcome " $\mathrm{C}$ ". 
to ANT, the nature of the middle actor is not relevant in this case. However, according to SAC, the source of the influence is a human provided of intentionality; hence, the actor on the left is always human. Fig. 17 brings a similar representation, but in this case, the actor in the middle is a mediator: distinct arrow lines represent the concept of forwarding different influences.

At every link in an association chain, influences may be transported by many carriers. Using Latour's own words [34, p. 204]: "what is being transported: information, traces, goods, plans, formats, templates, linkages, and so on". Joining this point of view to SAC we can distribute those carriers onto the semiotic ladder, showing how both theories encompass the influencing mechanisms (Fig. 18).

Axiologically, our proposal aligns to SAC, as it considers that the production of knowledge about a social phenomenon must return towards the participants of the phenomenon, so they can benefit from the results of the study. At the same time, its impact remains limited to what is expected from a study based on ANT, i.e., the contribution is the better understanding of who or what are the participants of the phenomenon, simultaneously highlighting the participation of technology in society and vice-versa.

From an epistemological point of view, there are socioconstructivist influences in both theories, such as concerns about the ontological dependence on SAC, and the dependency ANT points out on the process of recognizing an unknown actor using known actors to discover its affordances. For an inquiring actor, who tries to get knowledge about invariant patterns of behavior of the unknown entity, interactions between them may be mediated by other actors, these ones already known and recognized by the society the inquiring actor belongs. The possibilities of interaction with unknown actors are gradually clarified by means of performances onto it, as well as actions in the opposite direction - from the point of view of the inquiring actor, observations. This interaction may occur direct or indirectly, involving other intermediaries, human or non-human, which contain pre-existing concepts of the society and carry the stimuli and their effects, by physical or cognitive means, allowing the new actor to be understood. In both theories, there is a relationship of ontological dependency describing new concepts based on those who are already socially accepted (Fig. 19).

Although ANT and SAC adopt different methodologies, the former attempts to describe the observation of social

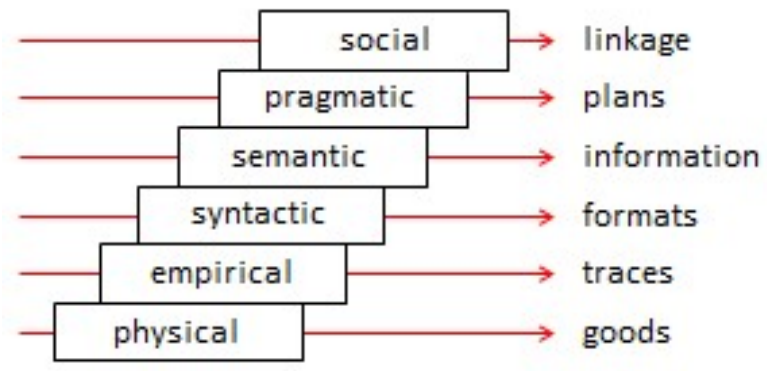

Fig. 18. Semiotic "ladder" showing the many possible entities circulating throughout associations and carrying interests.

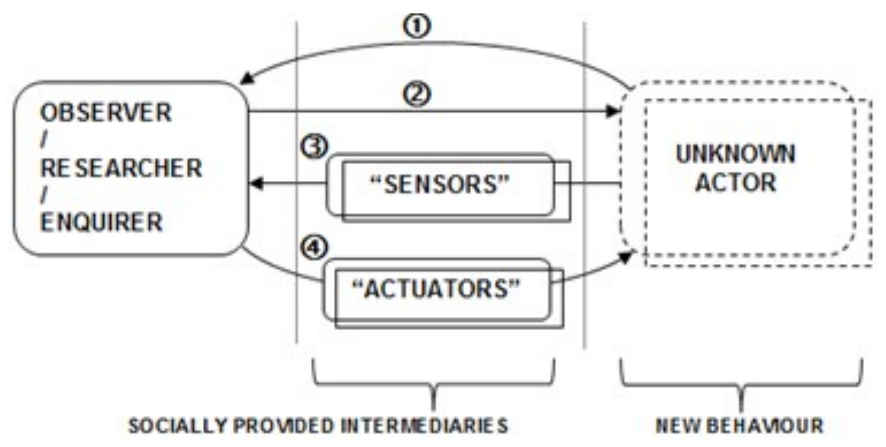

Fig. 19. Convergent epistemological conception between ANT and SAC: 1) direct observation; 2) direct action; 3) observation by other actor(s); 4) stimuli caused by other actor(s). The overlapping rectangles, with straight and rounded corners, mean either human or non-human can occupy the position.

phenomena, while the latter seeks to explain, capture and converge the concepts and standards governing an organized group of people, usually aimed at computerization. The methodology ANT proposes follows carefully the actors and their relationships, and this can be used to refine the identification and description of the participating entities and their influence on a social group.

In our approach, we interpret stakeholders as actors that act on each other via the networks they belong to, following association chains involving both human and non-human, as described by Akrich and Latour [1] and shown in Fig. 2. A stakeholder is defined by its ability to influence and be influenced by the technological artifact under study, and these influences should occur either directly, or through other actors, intermediaries or mediators. ANT helps to understand that for these influences to be effective there must be one or more paths to make the action of the stakeholders reach the others.

Given the "wicked problem" "scenarios expected for the joint application of ANT and SAC, in which intentions may not be clear, there may be conflict of interests, and users do not behave as expected by other stakeholders, we focus mediation at the pragmatic level, that is, the component of information system related to action, meaning and intention. Organizational Semiotics suggests the study of illocutionary acts to understand intentions as expressed through signs. Without the use of signs, agents are confined to their here-and-now environment $[39, \mathrm{p}$. 67]. ANT extends this understanding to propose that influences occur both by semiotic and material means [36], not only by the communication of interests, but also by any other influence that can shape the behavior of another actor.

The ANT point of view leads us to consider that the system under study may also be part of one or more chains of associations linking stakeholders, propagating influences between them. The technical system under study must be scrutinized for being used for negotiation and modification of behavior, namely the translation of interest. Not only its planned use, but also the very existence of the system can make it an intermediary or a mediator between stakeholders. Fig. 20 exemplifies possible paths of influence of stakeholders

1 An unclearly stated problem, with incomplete, contradictory, or changing requirements. 
onto the system and the effect of system on stakeholders, while Fig. 21 depicts how the system can be part of a path a stakeholder employs to affect another one.

In order to understand how a piece of software placed on the stakeholders' diagram is able to influence the behavior of other actors, we must consider not only the communication that happens among its users, but more broadly, all influences and actuations the elements of its user interface may cause on users. Semiotic Engineering proposed by Souza [53] adequately addresses the concept, asserting that there is a metacommunication between the designer of software and its users. This meta-communication would be one of several modes of influence unfolding throughout the software - in this case between two specific stakeholders: the designer and the user. Participation of software as actor also implies it possesses

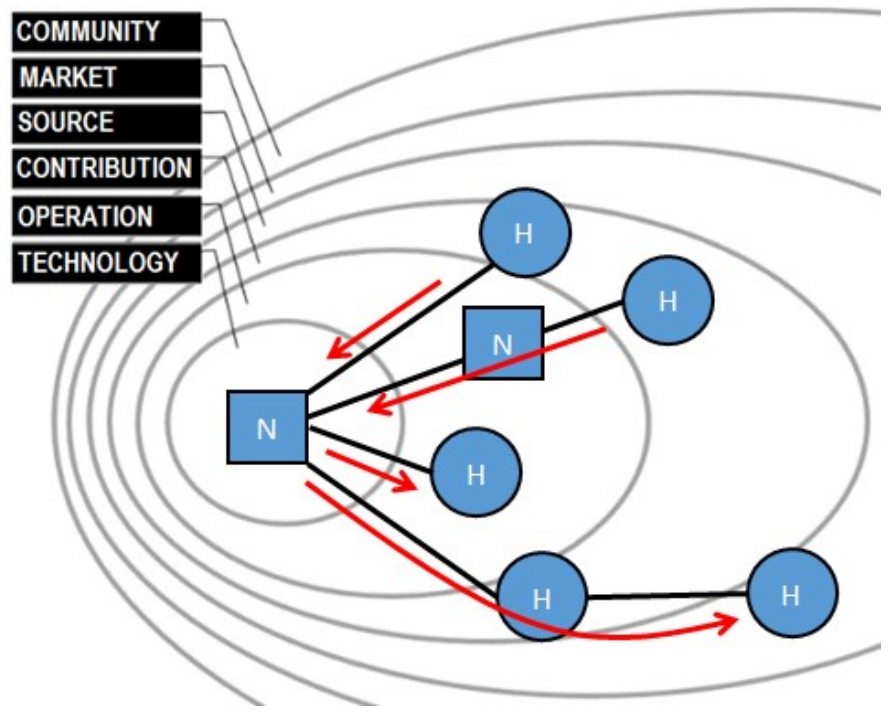

Fig. 20. Stakeholders affecting and being affected by the system, direct or indirectly.

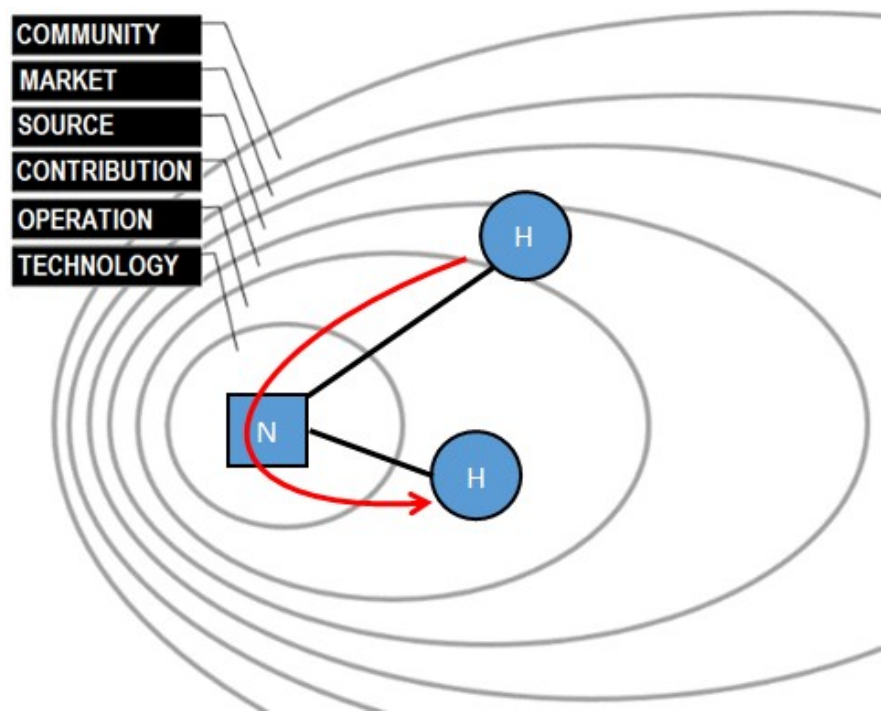

Fig. 21. Actors taking advantage of the system as a path to influence others some capability of promoting translation.

The proposal of Persuasive Design [20] is also aligned to this point of view, showing how technology can be designed to influence people's patterns of behavior. Defining persuasion as "an attempt to change attitudes or behaviors or both", it studies the actions of computers as tools, as media and as social actors, and presents some strategies to achieve such influence:

- by its physical presence and visual attractiveness;

- rewarding people with positive feedback (praising);

- modeling a target behavior or attitude and making it easier to accomplish to it;

- mimicking "personality traits" such as dominance or submissiveness;

- $\quad$ adopting social roles (referee, expert, authority);

- providing social support and taking advantage of social dynamics.

Knowing that the actions of a digital artifact may cause effects on the social setting surrounding it - and vice-versa may help in simultaneously shaping the hardware and software and, at the same time, enriching the discussion involving other stakeholders about their interests, expectations about the artifact being designed, and opportunities of catalyzing other stakeholders' needs towards a mutually benefic behavior.

TABLE I. SUMMARY OF PARADIGM COMPARISION

\begin{tabular}{|l|l|l|l|}
\hline Subject & ANT & SAC & Proposal \\
\hline Reality & Subjectivist & Subjectivist & Subjectivist \\
\hline Knowledge & $\begin{array}{l}\text { Socially } \\
\text { constructed }\end{array}$ & $\begin{array}{l}\text { Socially } \\
\text { constructed }\end{array}$ & $\begin{array}{l}\text { Socially } \\
\text { constructed }\end{array}$ \\
\hline Ontology & $\begin{array}{l}\text { Actors: no } a \\
\text { priori } \\
\text { distinction } \\
\text { between } \\
\text { human and } \\
\text { non-human }\end{array}$ & $\begin{array}{l}\text { Affordances } \\
\text { and } \\
\text { responsible } \\
\text { human (agents) }\end{array}$ & $\begin{array}{l}\text { Actors: human } \\
\text { must be } \\
\text { highlighted } \\
\text { when sources } \\
\text { of interests }\end{array}$ \\
\hline Behaviour & $\begin{array}{l}\text { Momentary } \\
\text { stabilized by } \\
\text { mutual benefit }\end{array}$ & $\begin{array}{l}\text { Focused on } \\
\text { invariant } \\
\text { patterns }\end{array}$ & $\begin{array}{l}\text { The invariant } \\
\text { patterns are } \\
\text { consequence of } \\
\text { mutual benefits }\end{array}$ \\
\hline
\end{tabular}

\section{A CASE STUdy OF APPLYING ANT + SAC CONCEPTS IN SOFTWARE DEVELOPMENT}

A common requirement in scientific projects is to carry out literature reviews regarding the subject to be studied. Prado et $a l$. [49] developed software - named Quid - intended to help scientists in this task, providing suggestions to improve a literature review, based on bibliographic data publically available on the Internet, and data fed directly on the system as well. In order to provide better and faster outcomes, this software depends on its local database to be kept up to date. To overcome this potential weakness, a functionality was developed to import data from the Brazilian scientific curricula database - named Lattes Platform - developed and maintained by the Brazilian National Council for Research - CNPq. 
However, this data is not always updated, and Quid requires the import procedure to be triggered manually only after data is reliable.

In this case study, we apply the aforementioned concepts to understand the sociotechnical network that this software participates, aiming to solve the particular problem of how to encourage people to keep their Lattes curriculum up to date and to use Quid to trigger the data fetch process afterwards. What we present here is an excerpt, for illustrative purpose.

Beginning from the stakeholder analysis and diagramming, as performed in SAC-based projects, some participants were mentioned: scientists (potential Quid users), Quid developers, the $\mathrm{CNPq}$, authors of scientific literature (Lattes users), and so on. Enriching this step with the ANT point of view, some other actors were found: non-human that are direct or indirect targets of interests of the previously identified stakeholders; for instance, Quid and Lattes systems. Performing a problematization phase of translation, we seek for potential paths to expand the network. One of them is the interest scientists have in maintaining a personal webpage listing their publications, not in a third-part application such as Researchgate $^{2}$, but instead in a website encompassing other research and teaching activities, byproducts, professional schedule and so on. A provisional stakeholder diagram was generated, as shown in Fig. 22, containing some paths for interests; for instance: the interest of developers to make users use Quid, the interests of Quid users to show their work to other scientists, and the interest of CNPq to make all scientists to use Lattes.

Heading the translation towards the interessement phase, it was suggested that Quid could assume the role of provider of content, as a web service, to be fetched by Ajax and embedded in any web page, following the layout style of such page. Thus, the effort to insert data into Lattes and triggering the Quid load procedure would be rewarded. However, it would require some effort of Quid developers to create a functionality not originally intended for the software - translation mode 1 . The suggestion was accepted by developers and welcomed by the members of a scientific project interested in publishing their bibliographic work in the project web page; therefore, reaching the enrollment stage of translation. Finally, as a way to ensure alternative paths to attract interests to use this feature, Quid developers added a word cloud generator, based on publication titles, which could also be embedded in any web page. The association between Quid and personal web pages create a new path to influence other actors, as depicted in Fig. 23: a new interest of users in load data into Quid may emerge, as long as it forwards to their personal web page, and therefore make this data available to other scientists know their work. Quid acts as a mediator, receiving this interest of scientists to upload data and translate it to have a personal webpage with their recent publications. As a plus, it may increase the interest of users in feeding their Lattes resumé, and aligns to the interests of its developers in keeping the Quid database up-to-date.

This analysis and design, however, covers only the social level of the semiotic ladder (Fig. 9). SAC states that all levels

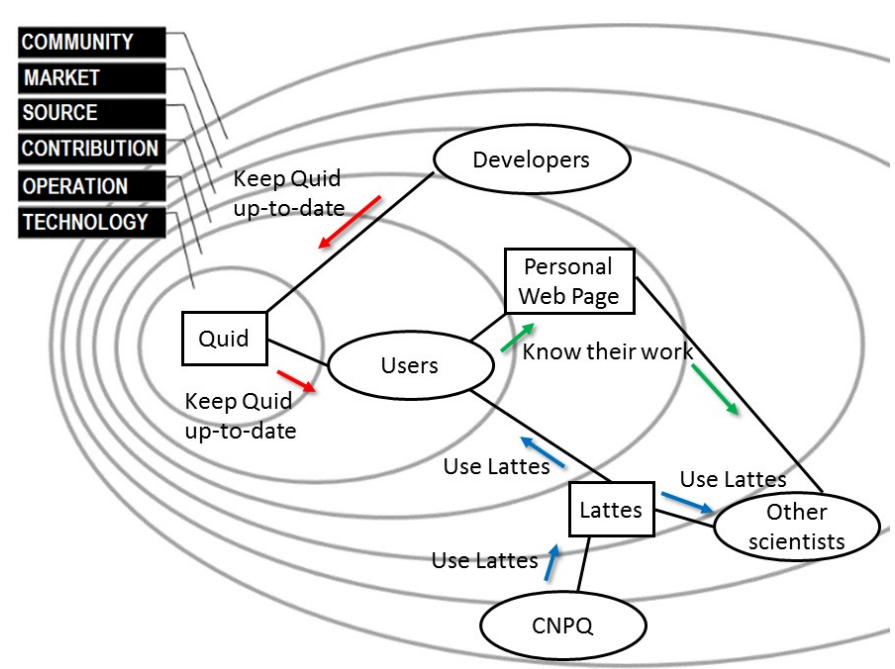

Fig. 22. Proposed stakeholder diagram, encompassing human and non-human actors.



Fig. 23. The association between Quid and the personal web page of its users reconfigures the network of actors, allowing other paths for interests. Quid is acting as a mediator.

must be addressed. From the pragmatic perspective, the idea of a trigger from persuasive design [20] was employed, by adding a well-positioned, distinctive feature on the user interface inviting them to improve the data being visualized. At the semantic level, the designers' message was chosen to be explicit ("Do you want to improve this data", providing also an explanation about the benefits of such action). The syntactic and lower levels borrow features from the Bootstrap ${ }^{3}$ framework used for implementation, allowing desktop and mobile browsers to share the same user interface, arranged in panels containing: scientist' identification, their list of publications, a word cloud from the titles of their publications, coauthors and so on. The final user interface is show in Fig. 24.

\footnotetext{
${ }^{3}$ http://getbootstrap.com/
} 


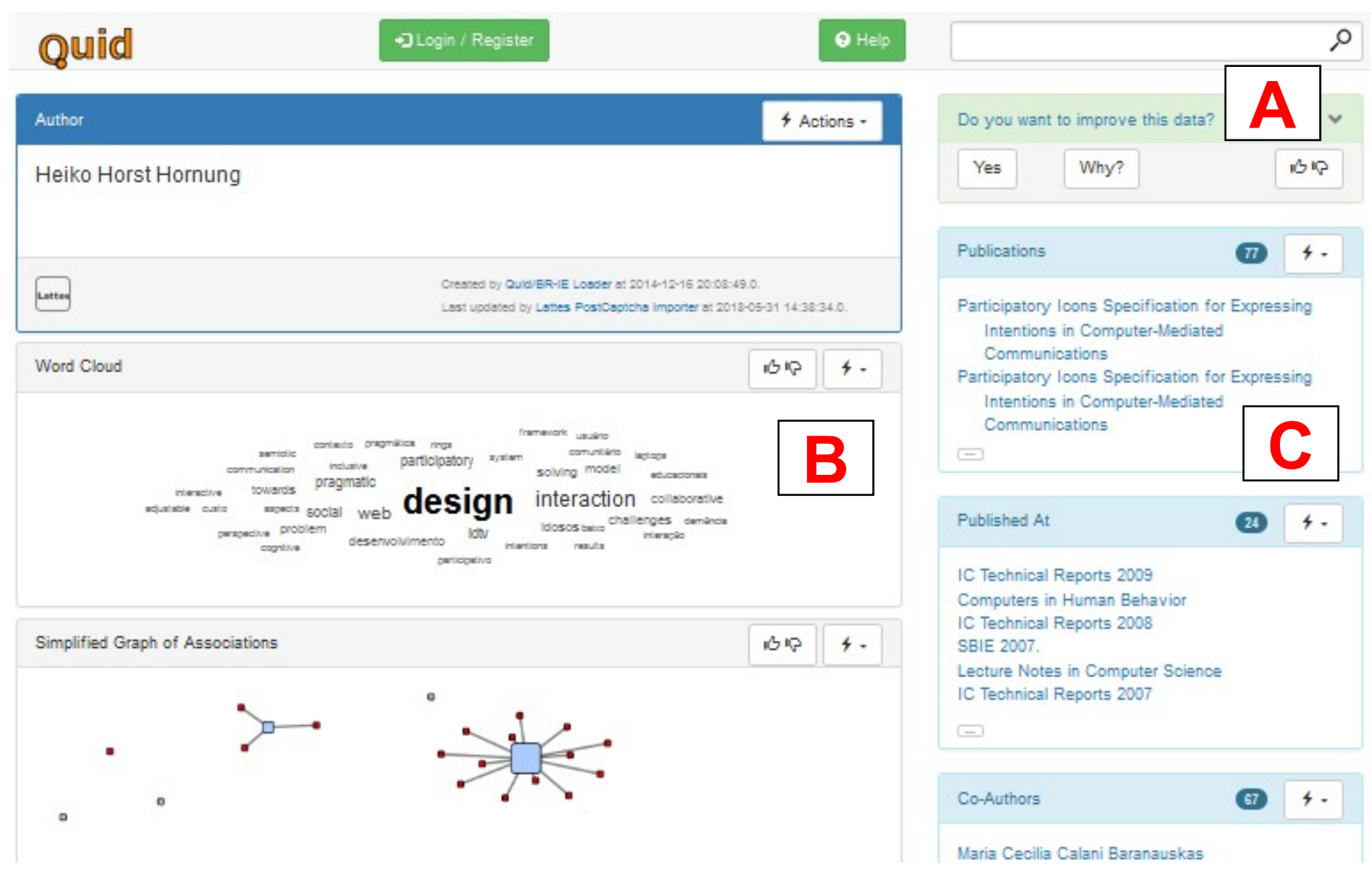

Fig. 24. Snapshot of Quid user interface. Details: (A) feature inviting users to help in update their data; (B) "word cloud" and (C) "publication list" - both can can be dinamically embedded in any other external web page using javascript.

\section{FUTURE PERSPECTIVES}

Current technology evolution is pushing the limits of our comprehension of the world and of ourselves. As Miccoli [42] states, even the "traditional characteristics of our unique humanity - our capacity to focus our attention on an objective (intentionality), our capacity to make choices (volition), and our capacity to reason in relation to those choices and objectives (logic)" have lost the status of singularities. These faculties, assessed from neurologic and physiological approaches, can also be seen as natural processes distributed across our biological substrates. Users' tendency of attributing intelligence, intentionality, or even personality to technological products has been "a longstanding concern in $\mathrm{HCl}$ " [14]. In fact, anthropomorphisation of (re)actions of inanimate entities is a psychological human feature studied since long ago [24]. Instead of insisting in a clear divide, recent design approaches [20] exploit this feature in favor of more socially participant devices.

Following this trend, theories to support the design of sociotechnical assemblies must point towards a blending of people and technology with blurred boundaries. In the following sections, we go further expanding the set of theoretical tools. Section VII-A brings an overview of Game Theory as an additional viewpoint to address people's choices and behavior from a formal and mathematical manner, bringing support to the idea that norms can be intentionally promoted to reach collective gains. Section VII-B introduces a statistical approach for non-deterministic behavior that fits both human and non-human, being aligned to SAC, ANT and Game Theory. Section VII-C discusses the unfolding of this point of view - based on probability, norms and network of heterogeneous actors - to the study of user interfaces. Next, Section VII-D speculates an eventual approximation of this ensemble of theories to another one, the Enactivism, as it matches the ideas of loops of actuations as the source of human knowledge - and the human mind as well. Finally, Section VIIE summarizes the perspectives.

\section{A. Basic topics in Game Theory}

Game theory is the science of logical decision making in humans, animals, and computers $[4,25]$. It provides formal definitions and mathematical support to understand behavior in situations of conflict and cooperation. Each participant or joint group of participants is considered a player who can choose a strategy among two or more available. In most cases, the same set of strategies are available for all players, and they are aware of it. Cooperative games allow players to discuss and commit to strategies beforehand, while in non-cooperative games such choices are made in separate. When studying its evolution over time, the simplest situation is a single round game, but they can also occur iteratively for a fixed period of time, or indefinitely.

Games can be classified according to several characteristics, mainly regarding the distribution of the outcomes - gains, benefits - according to the player's preferences. Competitive games are characterized by a fixed 
sum of the outcomes for all players. An extreme case is the zero-sum game, in which a gain for one player corresponds to an equivalent loss for the other. Coordination games, on the other hand, capture the structure of situations where the main interest for players is to take the same strategy as the other - in simpler words, either both gain or lose. There are also mixedmotive games, in which attempts by the players to maximize their individual gains without regard for the gains of others result in losses to all.

Bicchieri [8] shows how norms can affect the choice of strategies. A social norm has the power to transform a mixedmotive game into a coordination game. In her definition, social norms often go against our self-interest, but when players empirically perceive it provokes a change in the payoffs of the original game, they prefer to obey to the norm. She proposes a hypothetical mechanics to explain social norms, where its acceptance depends on some beliefs every individual have about the others:

- They believe a sufficiently large subset of the population conforms to the norm.

- They believe a sufficiently large subset of the population expects them to conform to the norm.

- Optionally they may believe a sufficiently large subset of the population prefers them to conform to the norm and may apply some sanction or reward according to their behavior.

Recent results corroborate this theory, using computational simulations to search for a "tipping point" in social dynamics the minimum parcel of a population that can initiate a change in social conventions by committing to a new pattern of behavior. Results varied from $10 \%$ to $50 \%$ of the initial population as the required to promote a stable change over time. Centola et al. [13] built models to predict the tipping point under specific circumstances and validate it carrying out experiments in real world online communities. Predictions show there is no correlation between population size and tipping point. However, the individual memory length influenced the outcomes: when participants consider only the latest interactions to decide to comply with a norm, the size of the critical mass is smaller. In experimental conditions, the adoption of the alternative convention by non-committed subjects followed the predictions. Across all 10 studied groups, the sizes of the committed minorities ranged between $15 \%$ and $35 \%$ of the total population - providing a more concrete parameter of what a "sufficiently large subset" must be.

\section{B. A statistical approach for mediators}

Human behavior is unpredictable by nature. However, when subject to social environments, certain invariants and constraints may emerge and can be observed. The NAM method used by SAC identifies and represents these patterns. It is left aside, however, the identification of the possible sources of influences responsible for these actions. As the authors have previously shown in another paper [48] and applied in an actual scenario [50], expectations one actor has about others' behavior can be represented using the norm syntax presented by Liu [39]. Whenever an actor A expects, influences, or forces some other actor B to perform some pattern of action $\mathrm{P}$, the detailed context of this attitude can be described by disclosing the source of influence A, as in the following formula:



According to SAC, behavioral norms do not imply in strict compliance to its terms. When performed by responsible agents, they can decide to follow a norm-conforming or a norm-breaking actual behavior - Stamper [55] recalls both norms and affordances are a matter of probability. As understood by ANT, in situations when the target actor B behaves as expected by A, B is acting as an intermediary. However, there are moments actors behave obeying or breaking norms in a non-deterministic manner regarding the stimuli they receive, hence, as mediators. Responsible agents may choose not to follow a prescribed behavior, taking a decision based on their knowledge and feeling - for example, when the operator of an unbalanced machinery refuses to put himself at risk. Technological devices may also present sometimes a behavior deviant from the expected. For instance, an antispam email filter may not be able to accurate identify all kinds of undesired messages - despite a good antispam have a high success rate, it is not possible to predict all possible spam formats, and sometimes it fails to provide the expected behavior.

For any given social norm to stand, the size of the set of actors who comply with it, let us call it $\left|\mathrm{B}^{\prime}\right|$ must be large in relation to the whole population $|\mathrm{B}|$. That is to say, a higher probability $\pi$ of some pattern of action being actually verified among a group of people is a necessary condition so this behavior is embodied as a norm for that social group. The likelihood of observance of norm-conforming actions drives decisions for individuals of that society [8].

$$
\pi=\frac{\left|B^{\prime}\right|}{|B|}
$$

We propose to apply this probabilistic approach to tackle the modeling and representation of mediator actors. Despite it is not possible to ensure which action a specific actor will take at a certain moment, it is possible to estimate the population probability over a period of time a behavior will occur, and representing this adding the following underlined line to the norm record:

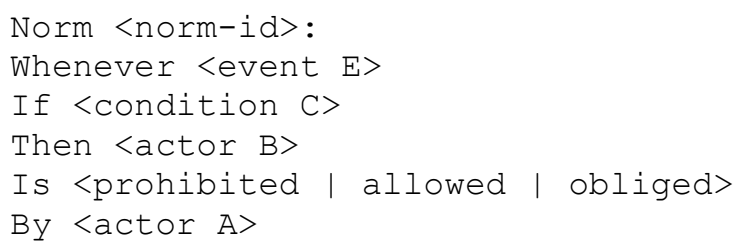




\section{With probability $\pi$ \\ To do <pattern of action $\mathrm{P}>$.}

This gives us some predictability about what to expect from the mediators, even when results may vary. The probability may also be monitored over time to validate changes or demand new strategies. For instance, recalling the case study presented in Section VI, it was observed on log files that from 4557 calls for help shown (Fig. 24 (A), top right), 36 were answered by users. That is to say, the Quid actor is being $\pi=$ $0.79 \%$ effective in translating the interests of developers into users' actions - what is far from the required to make it a normal user behavior. This can allow a designer to choose to persuade users by praise or reciprocity [20], or require the designer to emit a "social cue" showing previous users who have recently helped the improvement of Quid database, compelling other users to comply with the same behavior. Interesting to notice that this statistical approach can be applied both to human and nonhuman actors.

\section{Where will be the user interface?}

The Internet of Things - IoT - is providing the Human Comuputer Interaction area with new research challenges. For instance, Lingel [38] inquires us to think about the perils of having a multitude of apparently simple mundane objects around us that, in fact, are collecting data about us without our explicit awareness.

As participants of social settings, these "smart objects" must be designed as part of a more complex sociotechnical landscape. Once again, the norm well defined syntax is helpful to understand these shades. A simple stimulus-response behavior for an object can be represented by:

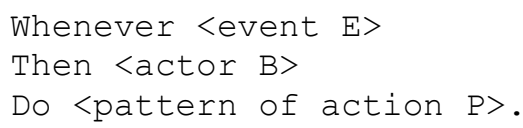

In case we are talking about smart objects with more complex embedded if-then rules, we can employ another element from the norm syntax:



Besides, regarding the deontic operators prohibit, allow and oblige, ANT informs us that "there might exist many metaphysical shades between full causality and sheer in-existence: things might authorize, allow, afford, encourage, permit, suggest, influence, block, render possible, forbid, and so on" [34]. More flexibility on norm representation can empower the analyst to catch more detailed nuances of the scenario being studied, specifying the influences transported in associations.

Most of these objects, however, are not standalone devices, but instead, networked artifacts capable of receiving and transmitting actions and stimuli. This network can be understood using the ANT + SAC approach presented before. Nevertheless, given its distributed nature, there is no "system" to which users interact - to give a sense of identity to the system, in a way that users can relate to it as a single predictable actor. Pursuing this "punctualization" - the blackboxing proposed by ANT - is not a simple task, as discussed by Miccoli [42, p.14]: “The perceived 'autonomy' of anything is functionally mythological. It is a projection which logically situates an entity in the perceived lifeworld. As humans, we base our specific autonomies on the perception that we are self-contained individuals. [...] To mitigate the implied spaces between a perceived self and a perceived world, we fall back on equally mythological 'interfaces' to bridge the gap between the autonomous self and the world that self occupies".

The ontological planarity proposed by ANT, in this case, propose a solution, in which an actor is defined by their associations, carrying stimuli to and fro. With this concept in mind, we envision a change in the concept of user interface, from the "surface" where system and users presents themselves to each other, to a set of paths carrying actions and influences to and from the user, towards something that can be perceived as a common end: the system. These concepts are sketched in Fig. 25.

It is not necessary that the "system" to be a single monolithic software or device, but instead, it has to give to the user the perception of loops of action that can be related to a single actor. Therefore, the mental model the user builds about the system is created incrementally from theses paths, as conceptually shown in Figures 13, 14 and 19.

If from one side, objects are gaining network access and a form of "virtual existence", from the other human are
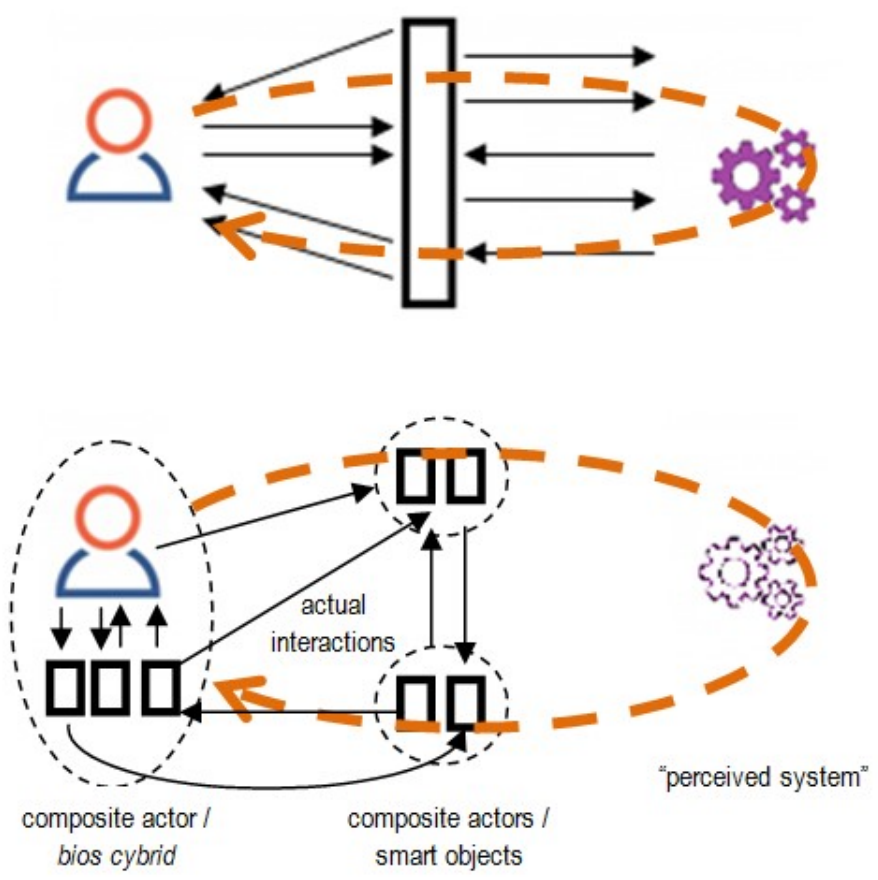

Fig. 25. Above: a traditional concept for user interface. Below: rethinking the user interface as a disperse set of devices which lead, direct or indirectly, to a perceived connection to a single responsive entity - the "system". 
becoming more strictly connected to devices, becoming a bios cybrid, a term coined by Domingues [16] meaning a biological-cybernetic hybrid. In fact, the association of the human with these near devices creates hybrid actors. To provide an analogy to discuss such composite actors, Latour [33] recalls the disarmament debate where one party defends that "guns kill people" - a materialist standpoint - and the other says "people kill people, not guns" - a more traditional sociological approach. He declares both as wrong; by the ANT point of view the presence of a gun in the hands of a person creates a new actor, the "gun-citizen or citizen-gun", a symmetrical translation which modifies the potential of action of the person and the gun as well.

For sake of illustration, let us consider a hypothetical scenario expanding the previous case study, aggregating new features for Quid. Suppose some University library uses personal RFID tags to allow access for students in a special collection room for rare books, unavailable in digital formats. The University can propose a joint service using Quid, the security system providing the student location for Quid whenever it happens. In its turn, Quid can verify if some of these books are referenced by some of the bibliographical research and/or may be useful for the student, and send a message to their cellphone. Despite all technological apparatus, the user must understand the whole action as "Quid knows I'm here and is trying to make me aware of something useful".

\section{Socio-enactive systems mediated by technical artifacts}

Asserting that a cognitive mind develops only in a close relation to its environment, Varela, Thompson and Rosch [56] proposed the concept of enaction. Enactivism proposes an alternative to the mind-body dualism, emphasizing the interactions between mind, body and the environment, seeing them all as inseparably intertwined in mental processes, where knowledge is constructed by an agent, using its sensorimotor apparatus to act upon its environment and receive actions from it. Enactivism is a criticism on how cognitive scientists standardly assume a division between independently existing "external" objects, properties and events on the one hand and their "internal" representations in the mind on the other hand a positivist stance [47]. Instead, Enactivism proposes cognition and environment are seen as inseparable: the external objects are delineated and the knowledge about them are internalized as a single phenomenon, driven by loops of action and reaction involving the mind and the world.

This idea was translated by Kaipainen et al. [27] into the concept of enactive systems, i.e., systems that create feedback loops using sensors and actuators, coupling to the sensorimotor apparatus of the users, as it exchanges energies and signals with the environment [17], as in the enactive condition described by Varela et al. [56]. Enactive systems have no core abstraction of the environment; the world itself is the representation, being continually sensed to regulate internal processes of the system. The human agent becomes a participant of this process rather than a user of tools. The goal of building enactive systems is that user interface becomes implicit, perhaps even to the degree of being nonconscious or directly hooked up to the participant's physiology, enhancing the action loops between mind and ambient to improve individual's sense-making.

This point of view is focused on single individuals; however, SAC recalls us that responsible agents are not only single persons, but also groups of people acting together with some identity. We envision that Enactivism can be expanded to collective cognitive beings, such as societies and communities. Moreover, it can deal with heterogeneous social networks, composed by humans and non-humans, in such a way that "inner states" of the social groups can be assessed. Having entered our daily lives tremendously, the technological products are able to reveal in detail people's patterns of behavior and practices. In this sense, they serve as "coethnographers" [21 apud 14]. These devices can act as social "sensors" and "actuators", providing feedback loops to create socio-enactive systems.

The single person physiological feedback loop of the original enactive system concept can be translated to a social context: as a novel understanding of social networks as composed of actors who are person-and-their-devices that provide distinct affordances for interaction and emergence of associations. Human-Computer Interaction research can deal with the adequate design of loops of actions and responses that mediate several other actors, a mediation that respects and promotes the values of the community of users. Brooks [11] states that complex and useful behavior of a system needs not necessarily be a product of an extremely complex programming; rather, it may be simply the cleverly tailored reflection of a complex environment. Hence, designing associations to external entities - the human and nonhuman actors who compose the complex environment - become as important as the project and knowledge of inner structures of such actors.

\section{E. Discussion on future perspectives}

Social situations can be studied from a Game Theory perspective, as introduced before [8]. In this sense, in everyday situations involving conflicts of individual and collective interests - a mixed-motive game - the adequate actuation of nonhuman/devices as social actors have the potential to reinforce or undermine behaviors, promoting desired social norms in the human participants and creating conditions beneficial for the interests of the whole group and of individual members as well - a coordination game.

As Pereira et al. [45] discussed, norms, values and culture are closely related, considering "norms as a concept able to support designers to move from informal understandings about values and culture of different stakeholders to their effective involvement and consideration in the resulting technical artifact". Our proposal goes further, showing that an adequate representation of norms is a first step towards the design of socially aware digital artifacts, which must be followed by the identification of sources and paths of influences resulting in those norms, and the careful choice of how and how much each influence must be forwarded.

All theoretical sources presented so far share a common subjectivist/constructivist stance. In addition, what can be seen as a weakness or source of criticism in one can be completed 
by the other. For instance, in the experimental setup of Centola et al. [13] the members of each group were matched at random into pairs to interact with one another. ANT poses as a viable theoretical stance to deal with more complex arrangements of people and objects, as graphs containing hubs, shorter paths and other topological features that can be adequately addressed. As another example, despite the fact that ANT receives critics about proposing agency for nonhumans, SAC offers the concept of responsibility. Finally, SAC deals with probabilities only qualitatively, while Game Theory does it quantitatively.

To synthesize the potential of the theoretical set presented so far - as a wireframe subject to be filled and strengthened we expect it can allow a designer to document, plan and observe the progress of:

- Patterns of behavior presented by people, devices and software;

- Sources of influence promoting the existing behavior;

- The path such influences take, including situations when people operate systems, and when systems sense people;

- Potential interests in novel behavior;

- The effectiveness of influences towards such changes;

- The extent of social impact, assessing whether localized mutual benefit spreads to provide collective welfare;

- The eventual need to intervene and a "map" of where to do it.

\section{FINAL REMARKS}

In the scenario of ubiquity of technology we are currently experiencing, there is a lack of theoretical frameworks and methodological instruments capable of modeling the sociotechnical networks of artifacts and people. This paper offers a concise overview of ANT and a bridge between it and other theoretical sources well-established in computer science. Our purpose was to shed light on complex organizational scenarios mediated by technology and its design.

This work contributes with a theoretically informed discussion on ANT and SAC seeking to build from both, based on the philosophy of science, towards a better understanding of the participation of technology in society and vice-versa. With this work, we provide an interpretation of ANT as a tool for computing researchers and practitioners to find and trace interests in complex organizational scenarios, offering a choice for theoretical and methodological support to understand and design heterogeneous aggregations of people and devices including digital artifacts.

A good research paradigm is the one that provides good open questions and the tools to answer them [31]. Moreover, it is the one capable to provide interchangeable immutable mobile results [32]. Facing the challenges of the Third HCI Wave [18], we believe that SAC and ANT together, supplemented with some concepts from Game Theory and
Enactivism, contribute with a precise representation of interests and influences in patters of actions, translatable across several manifestations of technical systems, such as web, mobile, wearables, natural interfaces, IoT and so on, addressing social features in a seamless connection with technology and the material world.

\section{REFERENCES}

[1] Madeleine Akrich, Bruno Latour, "A Summary of a Convenient Vocabulary for the Semiotics of Human and Nonhuman Assemblies". In Bijker \& Law - Shaping Technology / Building Society: Studies in Sociotechnical Change, 1992.

[2] Jonathan P. Allen, "Redefining the network: enrollment strategies in the PDA industry". Information Technology \& People, Vol. 17, pp. 171 185, 2004.

[3] Antonio D. Andrade, "From Intermediary to Mediator and Vice Versa: On Agency and Intentionality of a Mundane Sociotechnical System". Hershey, PA: Information Science Reference, 2012.

[4] Robert J. Aumann, "Game theory." Game Theory. Palgrave Macmillan, London, 1989.

[5] Cecília Baranauskas, "Socially Aware Computing". In: Proceedings of the VI International Conference on Engineering and Computer Education - ICECE, 2009.

[6] Cecília Baranauskas, Maria Cecília Martins, José Armando Valente. Codesign de Redes Digitais: tecnologia e educação a serviço da inclusão social. Penso Editora, 2013.

[7] Cecilia Baranauskas, Marleny Luque Carbajal, "The Social Nature of Programming: Children and Fluency". In International Conference on Human-Computer Interaction, pp. 291-308. Springer, Cham, 2017.

[8] Cristina Bicchieri, The Grammar of Society - the nature and dynamics of social norms. Cambridge University Press, 2006.

[9] David Bloor, Knowledge and social imagery. London, Routeledge \& Kegan Paul, 1976.

[10] Rodrigo Bonacin, Cecilia Baranauskas, Kecheng Liu, "From Ontology Charts to Class Diagrams - semantic analysis aiding systems design". In Proceedings of the Sixth International Conference on Enterprise Information Systems, ICEIS, pages 389-395, 2004.

[11] Rodney Brooks, "A Robust Layered Control Syste For A Mobile Robot". In IEEE Journal of Robotics and Automation, Vol RA-2, N.01, March, 1986.

[12] Michel Callon, "Some Elements of a Sociology of Translation: Domestication of the Scallops and the Fishermen of St Brieuc Bay". In John Law (ed.), Power, Action and Belief: A New Sociology of Knowledge, 1986.

[13] Damon Centola, Joshua Becker, Devon Brackbill, Andrea Baronchelli, "Experimental evidence for tipping points in social convention". Science Magazine, 360, pp. 1116-1119, June 2018.

[14] Nazli Cila, Iskander Smit, Elisa Giaccardi and Ben Kröse, "Products as Agents: Metaphors for Designing the Products of the IoT Age". Proceedings of the Proceedings of the 2017 ACM-CHI Conference on Human Factors in Computing Systems, Denver, CO, USA, 2017.

[15] Renato Dagnino, Science neutrality and technological determinism. Editora da Unicamp, 2008.

[16] Diana Domingues; Suzete Venturelli. "Cibercomunicação cíbrida no continuum virtualidade aumentada e realidade aumentada. Era uma vez ... a realidade". ARS (Publication of Escola de Comunicações e Artes da Universidade de São Paulo) vol.5 no.10. ISSN 2178-0447, 2007.

[17] Diana Domingues, Cristiano Jacques Miosso, Suélia F. Rodrigues, Carla Silva Rocha Aguiar, Tiago F. Lucena, Mateus Miranda, Adson F. Rocha, and Ramesh Raskar. "Embodiments, Visualizations, and Immersion with Enactive Affective Systems". Edited by Margaret Dolinsky and Ian E. McDowall. The Engineering Reality of Virtual Reality, 2014.

[18] Emanuel Felipe Duarte, Cecilia Baranauskas, "Revisiting the Three HCI Waves". In: Proceedings of the 15th Brazilian Symposium on Human Factors in Computer Systems - IHC '16. New York: ACM Press, 2016. 
[19] Samer Faraj, Dowan Kwon, Stephanie Watts, "Contested artifact: technology sensemaking, actor networks, and the shaping of the Web browser". Information Technology \& People, 17(2), 186-209, 2004.

[20] B. J. Fogg, Persuasive Technology - Using Computers to Change What We Think and Do. A volume in Interactive Technologies, 2003.

[21] Elisa Giaccardi, Chris Speed, Nazli Cila and Melissa L. Caldwell, "Things as co-ethnographers: Implications of a thing perspective for design and anthropology". In Design Anthropological Futures, Rachel C. Smith, Kasper T. Vaskilde, Mette G. Kjaersgaard, Ton Otto, Joachim Halse, Thomas Binder (eds.). Bloomsbury Academic, 235-248, 2016.

[22] Fabricio Matheus Gonçalves, Emmanuel Felipe Duarte, Julio Cesar dos Reis and Maria Cecilia Calani Baranauskas, "An Analysis of Online Discussion Platforms for Academic Deliberation Support". In International Conference on Social Computing and Social Media, pp. 91-109. Springer, Cham, 2017.

[23] Edward Hall, The Silent Language. Anchoor Books, New York, 1959.

[24] Fritz Heider and Marianne Simmel, "An Experimental Study of Apparent Behavior", the America Journal of Psychology, Vol 57, n. 2, pp. 243-259, University of Illinois Press, 1944.

[25] Henry R. Hermann, Dominance and Aggression in Humans and Other Animals: The Great Game of Life. Academic Press, 2017.

[26] Heiko Hornung, Interaction Design in the Pragmatic Web - Reducing Semiotic Barriers to Web-mediated Collaboration. Ph.D. thesis. Institute of Computing, State University of Campinas, 2013.

[27] Mauri Kaipainen, Niklas Ravaja, Pia Tikka, Rasmus Vuori, Roberto Pugliese, Marco Rapino and Tapio Takala, "Enactive systems and enactive media: Embodied human-machine coupling beyond interfaces". Leonardo 44(5), pp. 433- 438, 2011.

[28] Martin Kolkman, Problem Articulation Methodology. Ph.D. Thesis. University of Twente, Enschede, 1993.

[29] Travis Kriplean, Jonathan T. Morgan, Deen Freelon, Alan Borning, Lance Bennett, "Supporting reflective public thought with ConsiderIt". In: Proceedings of the ACM Conference on Computer Supported Cooperative Work, pp. 265-274, 2012.

[30] Peter Kroes, The moral significance of technical artefacts. Springer Science+Business Media B.V., 2012.

[31] Thomas Kuhn, The structure of Scientific Revolutions. The University of Chicago Press, 1970.

[32] Bruno Latour, Science in action: How to Follow Scientists and Engineers through Society. Harvard University Press, 1987.

[33] Bruno Latour, "On technical mediation - philosophy, sociology, genealogy”. In Common Knowledge, fall 1994, V3. N2, 1994.

[34] Bruno Latour, Reassembling the Social: An Introduction to ActorNetwork-Theory. Oxford University Press, 2005.

[35] Bruno Latour, Pablo Jensen, Tommaso Venturini, Sébastian Grauwin, Dominique Boullier, "The whole is always smaller than its parts - a digital test of Gabriel Tardes' monads". British Journal of Sociology, 2012.

[36] John Law, "Actor-Network Theory and Material Semiotics". The New Blackwell Companion to Social Theory. Blackwell Publishing Ltd., 2009.

[37] Heejin Lee, Sangjo Oh, "A standards war waged by a developing country: Understanding international standard setting from the actornetwork perspective". The Journal of Strategic Information Systems 15(3), 2006.

[38] Jessica Lingel, "The Poetics of Socio-Technical Space: Evaluating the Internet of Things Through Craft". In Proceedings of the 2016 CHI Conference on Human Factors in Computing Systems (CHI '16). ACM, New York, NY, USA, 815-826, 2016.
[39] Kecheng Liu, Semiotics in information systems engineering. Cambridge University Press, 2000.

[40] Kecheng Liu, Weizi Li, Organisational Semiotics for Business Informatics. Routledge Books, 2014.

[41] Ronald L. Mace, Graeme J. Hardie, Jaine P. Place, Accessible environments: Toward universal design. Center for Accessible Housing, North Carolina State University, 1990.

[42] Anthony Miccoli, "Posthuman Topologies: thinking through the hoard". In Design, Mediation and the Posthuman, Denis Weiss, Amy Propen and Colbey Emmerson Reid (eds), 2014.

[43] Michael J. Muller, Jean Hallewell Haslwanter, Tom Dayton. "Participatory Practices in the Software Lifecycle". In Handbook of Human-Computer Interaction, Chapter 11, 1997.

[44] Roberto Pereira, Cecília Baranauskas, "A value-oriented and culturally informed approach to the design of interactive systems". Int. J. Hum.Comput. Stud. 80, 2015.

[45] Roberto Pereira, M. Cecília C. Baranauskas, and Kecheng Liu, "On the relationships between norms, values and culture: preliminary thoughts in HCl". International Conference on Informatics and Semiotics in Organisations. Springer, Cham, 2015.

[46] Roberto Pereira, Samuel Bastos Buchdid, M. Cecília C. Baranauskas, "Values and Cultural Aspects in Design: Artifacts for Making Them Explicit in Design Activities". In J. Cordeiro et al. (Eds.): ICEIS 2012, LNBIP 141, pp. 358-375, 2013. DOI: 10.1007/978-3-642-40654-6_22, Springer-Verlag Berlin Heidelberg, 2012.

[47] Joseph G. Ponterotto, "Qualitative research in counseling psychology: a primer on research paradigm and philosophy of science". Journal of counseling psychology, 2005.

[48] Alysson Prado, Cecilia Baranauskas, "Capturing Semiotic and Social Factors of Organizational Evolution". In: Hammoudi S., Cordeiro J., Maciaszek L., Filipe J. (eds) Lecture Notes in Business Information Processing, vol. 190, Springer, 2014.

[49] Alysson Prado, Cecília Baranauskas, Ig Bittencourt, Fabrício Gonçalves, "Expandindo revisões bibliográficas sistemáticas pela análise de redes sócio-técnicas científicas". In Anais do XXXIV Congresso da Sociedade Brasileira de Computação - CSBC, 2014.

[50] Alysson Prado, Cecília Baranauskas, "Using stakeholder and pragmatic analyses to clarify the scenario of data sharing in scientific software". Anais da 17th International Conference on Informatics and Semiotics in Organisations (ICISO), IFIP WG8.1 Working Conference, Campinas, SP, 2016.

[51] Maria Carolina Santos, Bruna Bertãozini, Vânia Néris, "Studies in Organisational Semiotics: A Systematic Literature Review". Proceedings of the ICISO 2016. Socially Aware Organisations and Technologies - impacts and Challenges, 2016.

[52] Douglas Schuler, Aki Namioka, Participatory Design: Principles and Practices. Lawrence Erlbaum Associates, 1993.

[53] Clarisse Sieckenius de Souza, The Semiotic Engineering of Humancomputer Interaction. The MIT Press, 2005.

[54] Maiko Spiess, Abrindo o código: a rede tecno-econômica do BrOffice.org. M.Sc. dissertation. Geosciences Institute, State University of Campinas, 2010.

[55] Ronald K. Stamper, "Organisational Semiotics: Informatics without the Computer?" In: Liu K., Clarke R.J., Andersen P.B., Stamper R.K. (eds) Information, Organisation and Technology. Information and Organisation Design Series, vol 1. Springer, Boston, MA, 2001.

[56] Francisco J. Varela, Lydia Thompson, and Eleanor Rosch, The embodied mind: Cognitive science and human experience. The MIT Press, 1991. 